\title{
Implementação da Metodologia Lean Six Sigma em uma indústria química
}

\section{Implementation of the Lean Six Sigma Methodology in a chemical industry}

\author{
Luana Carvalho Luiz Engenheira de Produção. Universidade Tecnológica Federal do Paraná - Ponta Grossa \\ (UTFPR-PG) - Brasil. luanacarvalholuiz@gmail.com. \\ Jean Marcell Lara Tybuszeusky Engenheiro de Produção. Universidade Tecnológica Federal do Paraná - Ponta Grossa \\ (UTFPR-PG) - Brasil. jean._marcell@hotmail.com \\ Daiane Maria De Genaro Chiroli Doutora em Engenharia de Produção. Universidade Tecnológica Federal do Paraná - Ponta \\ Grossa (UTFPR-PG) - Brasil. daianechiroli@utfpr.edu.br
}

\begin{abstract}
RESUMO
Diante das mudanças ocorridas no ambiente industrial e do aumento da competitividade entre as empresas, houve a busca por melhorias nos modelos de gestão utilizados para a produção dos produtos. Dentre as metodologias utilizadas, destaca-se o Lean Six Sigma, que tem sido implementada em diferentes ambientes fabris, apresentando como finalidade a redução da variabilidade e eliminação dos defeitos, que, por consequência, gera resultados positivos em relação à satisfação dos clientes e aumento na produtividade, além do incremento na receita. Diante deste contexto, o presente trabalho tem por objetivo realizar um estudo da implementação da metodologia Lean Six Sigma em uma indústria do setor químico, sendo caracterizado como um estudo de caso. Para isso, faz-se uso da metodologia DMAIC, incorporando ferramentas da qualidade e do Six Sigma para identificar e propor melhorias em partes do processo produtivo que apresentam falhas. A superprodução foi o tipo de desperdício estudado pelo trabalho no contexto organizacional e, no período de dois meses de análise, esta totalizou $285,16 \mathrm{Kg}$ de produto acabado, o que correspondeu a R\$ 905,75 em termos financeiros. Desta maneira, o custo anual das sobras é equivalente a $\mathrm{R} \$ 5.434,50$. As soluções levantadas para o problema foram organizadas com o auxílio da ferramenta $5 \mathrm{~W} 2 \mathrm{H}$ e estão relacionadas principalmente à correta mensuração dos insumos de produção e água utilizados no processo.
\end{abstract}

Palavras-chave: Lean Six Sigma. DMAIC. Superprodução.

\begin{abstract}
Due to the changes occurred in the industrial environment and the increase in competitiveness among companies, there has been a search for improvements in the management models used for production of products. Among the methodologies used, Lean Six Sigma stands out. It is implemented in different factory environments, aiming variability reduction and defects elimination, which consequently create positive results in relation to customer satisfaction and productivity increase, besides revenue increase. In this context, the present work aims at conducting a study on the implementation of the Lean Six Sigma methodology in an industry of the chemical sector, thus, being characterized as a case study. In order to achieve this purpose, the DMAIC methodology was used, incorporating quality and Six Sigma tools to identify and propose improvements in those parts of the productive process that had shown failures. Overproduction in the organizational context was the kind of wastage studied by this work, and it totalled $285,16 \mathrm{~kg}$ of finished product within 2 months of analysis, which corresponds to $\mathrm{R} \$ 905,75$ in financial terms. Therefore, the annual cost of the leftovers is equivalent to $R \$ 5.434,50$. The solutions provided for the problem were organized with the support of the $5 \mathrm{~W} 2 \mathrm{H}$ tool and they are mostly related to the correct measuring of the production supplies and water used in the process.
\end{abstract}

Key-words: Lean Six Sigma. DMAIC. Overproduction.

Recebido em 19/02/2020. Aprovado em 01/04/2020. Avaliado pelo sistema double blind peer review. Publicado conforme normas da ABNT. http://dx.doi.org/10.22279/navus.2020.v10.p01-18.1202 


\section{INTRODUÇÃO}

A crescente competitividade entre as organizações fez com que a procura por inovação em modelos de gestão se intensificasse, pois com novos modelos de gestão, ocorre a otimização do desempenho de processos produtivos e eliminação de desperdícios. O objetivo de melhorar o processo produtivo está diretamente ligado a oferecer aos clientes um produto ou serviço de qualidade, de acordo com o que foi especificado. Contudo, a qualidade não é definida apenas como a entrega de um produto conforme, mas sim como um conjunto de práticas adotadas pela organização.

A utilização da tecnologia voltada às técnicas de produção se torna uma grande aliada no aumento da competitividade, pois engloba conhecimento técnico e prático (know-how) aos meios de produção, garantindo a melhoria das características do produto e do processo, e, consequentemente, a melhoria da qualidade. Metodologias associadas à melhoria contínua têm sido incorporadas aos processos das organizações, visando a integração de todos os seus setores e colaboradores, além de poder contar com um processo mais eficiente. Neste cenário, uma das metodologias que se relacionam com estes princípios é o Lean Six Sigma (SAKUMOTO; DE GENARO CHIROLI; DZULINKI, 2019; CONCEIÇÃO et al., 2019; SABA e SILVA; DE GENARO CHIROLI, 2020).

O Lean Six Sigma (LSS) é a combinação da filosofia Lean Manufacturing e Six Sigma, que abordam conceitos distintos, porém complementares. $\mathrm{O}$ Lean Manufacturing tem por objetivo reduzir o esforço humano, estoques, tempo de entrega e espaço de produção para atender a demanda do mercado. Já o Six Sigma é focado em reduzir a variabilidade do processo, aumentar a satisfação do cliente e a lucratividade da empresa. Esta metodologia faz uso de ferramentas estatísticas e de um método estruturado para a resolução de problemas (SABA e SILVA; DE GENARO CHIROLI, 2020; STAATSA; BRUNNERB; UPTON, 2011, WERKEMA, 2012).

Diante do cenário onde as empresas buscam por tecnologias para melhorar seu processo, se situa a indústria química brasileira, que está mais voltada ao mercado interno e apresenta a necessidade de agregar valor aos seus produtos, pois a matéria-prima utilizada é cara e as indústrias podem apresentar altos custos de produção, o que inviabiliza a competição no mercado externo (CHIROLI et al., 2016; MOREIRA; ARBACHE, 2016).

Em 2017, a indústria química brasileira exportou cerca de US\$13,6 bilhões e importou US\$ 36,8 bilhões, apresentando déficit na balança comercial. Neste mesmo ano, a indústria química representou $2,4 \%$ do PIB total brasileiro, contando com US\$ 7,6 bi de faturamento líquido relacionado a produtos de limpeza e afins, sendo este o segmento no qual atua a empresa objeto de estudo do trabalho (ABIQUIM, 2017).

Desta maneira, o presente trabalho visa responder ao seguinte questionamento: Quais os benefícios que a implementação do Lean Six Sigma pode trazer para uma indústria de produtos químicos?

Um dos desafios enfrentados pela indústria química, objeto de estudo do trabalho, diz respeito a atender aos clientes com urgência, uma vez que alguns clientes industriais requisitam os produtos quando seu estoque está acabando, entretanto, tais produtos são necessários para a continuidade de seu processo produtivo, o que pode ocasionar sérios transtornos na ocorrência da falta do produto. Desta maneira, para atender ao cliente que solicita o produto com urgência, a indústria química precisa acelerar seu processo de atendimento ao cliente, modificando o planejamento da produção. Apesar disso, algumas vezes não é possível atendê-lo, pois o prazo solicitado pelo cliente é curto e não compatível com o tempo de processamento da indústria química, ou o estoque de matéria-prima não é suficiente para assumir o pedido. Além disso, é de conhecimento dos responsáveis pela produção que o processo possui perdas, sendo necessário identificar onde elas ocorrem e encontrar maneiras de atuar sobre esta situação. 
Em relação à relevância do trabalho para a pesquisa acadêmica, o trabalho de Raval, Kant e Shankar (2018) analisou 190 artigos que continham o termo Lean Six Sigma presente no título, sendo que a finalidade de tal estudo era realizar um levantamento bibliográfico dos trabalhos que foram publicados entre os meses de janeiro de 2000 e setembro de 2016 envolvendo a temática. Tal trabalho foi realizado levando em consideração 6 diferentes bases de dados. Dentre os trabalhos analisados por Raval, Kant e Shankar (2018), apenas três deles possuíam a aplicação do Lean Six Sigma voltada para a área química, sendo todos os três trabalhos voltados à implementação de ferramentas do LSS em um laboratório. Neste sentido, percebe-se também a relevância acadêmica deste trabalho, uma vez que a temática não é tão recorrente em indústrias químicas.

Portanto, este trabalho se justifica por, através da utilização da metodologia Lean Six Sigma, mapear o processo produtivo e identificar as falhas existentes, buscando atuar sobre estas falhas e manter o foco nas atividades que agregam valor ao produto. Com isto, espera-se a melhoria do desempenho da organização, aumentando a eficiência de seus processos. Este trabalho tem por objetivo geral realizar um estudo da implementação da metodologia Lean Six Sigma, em uma indústria do setor de fabricação de produtos químicos.

\section{LEAN SIX SIGMA}

O Lean Six Sigma (LSS) é a integração da filosofia Lean Manufacturing e Six Sigma, que foram integradas para se complementarem, pois enquanto o Six Sigma se utiliza de ferramentas estatísticas e de um método estruturado para a resolução de problemas, o Lean Manufacturing tem seu foco em melhorar a velocidade do processo e reduzir o tempo de produção (WERKEMA, 2012).

A ideia fundamental do Lean Manufacturing é atuar sobre os desperdícios e a ideia relacionada ao Six Sigma é a eliminação da variação do processo. Com a ajuda do Lean é possível alcançar a simplicidade nas operações e o processo fica mais rápido. E a aplicação do Six Sigma colabora para o gerenciamento da complexidade presente no processo, tornando-o melhor. Ambas, trabalhando em conjunto, levam à melhoria do desempenho (WERKEMA, 2012).

O Lean Six Sigma, consiste na combinação da manufatura enxuta com a metodologia de melhoria Six Sigma. Em suma, o LSS é uma abordagem voltada à melhoria e pode ser entendido também como uma estratégia de negócios que aprimora o desempenho do processo e resulta na satisfação do cliente, permitindo, através do uso de ferramentas, que hajam mudanças no processo considerado (SNEE, 2010; DROHOMERETSKI et al., 2014).

Com relação ao objetivo final, tanto o Lean quanto o Six Sigma têm como propósito atingir a qualidade por toda parte, desde o serviço prestado ao cliente até a educação da força de trabalho, com o pensamento cultural direcionado às melhorias. É importante lembrar também que a ideia de atuar sobre a causa raiz de um problema identificado deve sempre ser seguida, pois é mais efetivo do que tratar apenas os sintomas, eliminando a fonte dos problemas (SALAH; RAHIM; CARRETERO, 2010; SNEE, 2010).

Pepper e Spedding (2010) abordam sobre a importância da integração entre o Lean e o Six Sigma quando ocorre sua implantação, pois pode ocorrer que essas duas filosofias sejam aplicadas de maneira isolada, quando não era a intenção inicial, resultando em uma aplicação ineficaz tanto do Lean quanto do Six Sigma, criando duas subculturas dentro da organização que competem entre si pelos mesmos recursos. 


\subsection{DMAIC}

O Six Sigma é conduzido pela metodologia DMAIC, que consiste em cinco fases: Definir (Define), Medir (Measure), Analisar (Analyze), Melhorar (Improve) e Controlar (Control), dando origem a sigla DMAIC. O modelo DMAIC tem como objetivo aperfeiçoar as pessoas e os processos para obter melhoria no desempenho e nos resultados (MARTINELLI, 2009; WHEELER, 2010).

O DMAIC é um método sistemático e disciplinado, que se baseia em dados e no uso de ferramentas estatísticas, sendo que em cada fase do DMAIC são utilizadas diversas ferramentas que ajudam a organização a alcançar os resultados desejados (CARVALHO; PALADINI, 2012).

\section{METODOLOGIA}

O propósito deste trabalho é aplicar a metodologia Lean Six Sigma no setor fabril. Para tal, buscouse uma indústria ativa no mercado disposta a disponibilizar informações internas, de maneira íntegra, para aplicação do Lean Six Sigma. A indústria que aceitou ser objeto de estudo do trabalho, atua no ramo de fabricação de produtos químicos para limpeza e manutenção empresarial, está situada na região dos Campos Gerais, no estado do Paraná.

A estrutura organizacional desta empresa está disposta da seguinte maneira: diretoria, administração, comercial e produção, apresentando um quadro de 13 colaboradores. Trata-se de uma empresa de pequeno porte, pois possui faturamento menor ou igual a $R \$ 3,6$ milhões. Apresenta um sistema de produção intermitente com processo de manufatura em jobbing, contando com aproximadamente 300 produtos.

A metodologia DMAIC deve ser utilizada para que haja integração entre o Lean e o Six Sigma (SALAH; RAHIM; CARRETERO, 2010). A partir disso, estruturou-se o planejamento da metodologia deste trabalho, de maneira que o DMAIC seja dividido entre coleta de dados e análise dos dados. No entanto, vale ressaltar que o presente trabalho contempla apenas as três primeiras fases da metodologia DMAIC, que corresponde às fases definir, medir e analisar.

No procedimento de coleta de dados (Figura 1) abordam-se as fases definir (define) e medir (measure), representadas pelas letras D e M da sigla DMAIC. Já no procedimento de interpretação e análise de dados, contempla-se a fase analisar (analyze).

Como pode ser visualizado na Figura 1, a primeira etapa relacionada à coleta de dados diz respeito a conhecer o processo produtivo da empresa, para que as etapas seguintes possam ser executadas. Após o conhecimento do funcionamento do processo da empresa, houve a elaboração do fluxograma, sendo detalhadas as etapas observadas. Também foi desenvolvida a ferramenta SIPOC, voltada ao mapeamento do processo, para compreender o fluxo de produção, bem como suas entradas e saídas. 
Figura 1 - Procedimento de coleta de dados

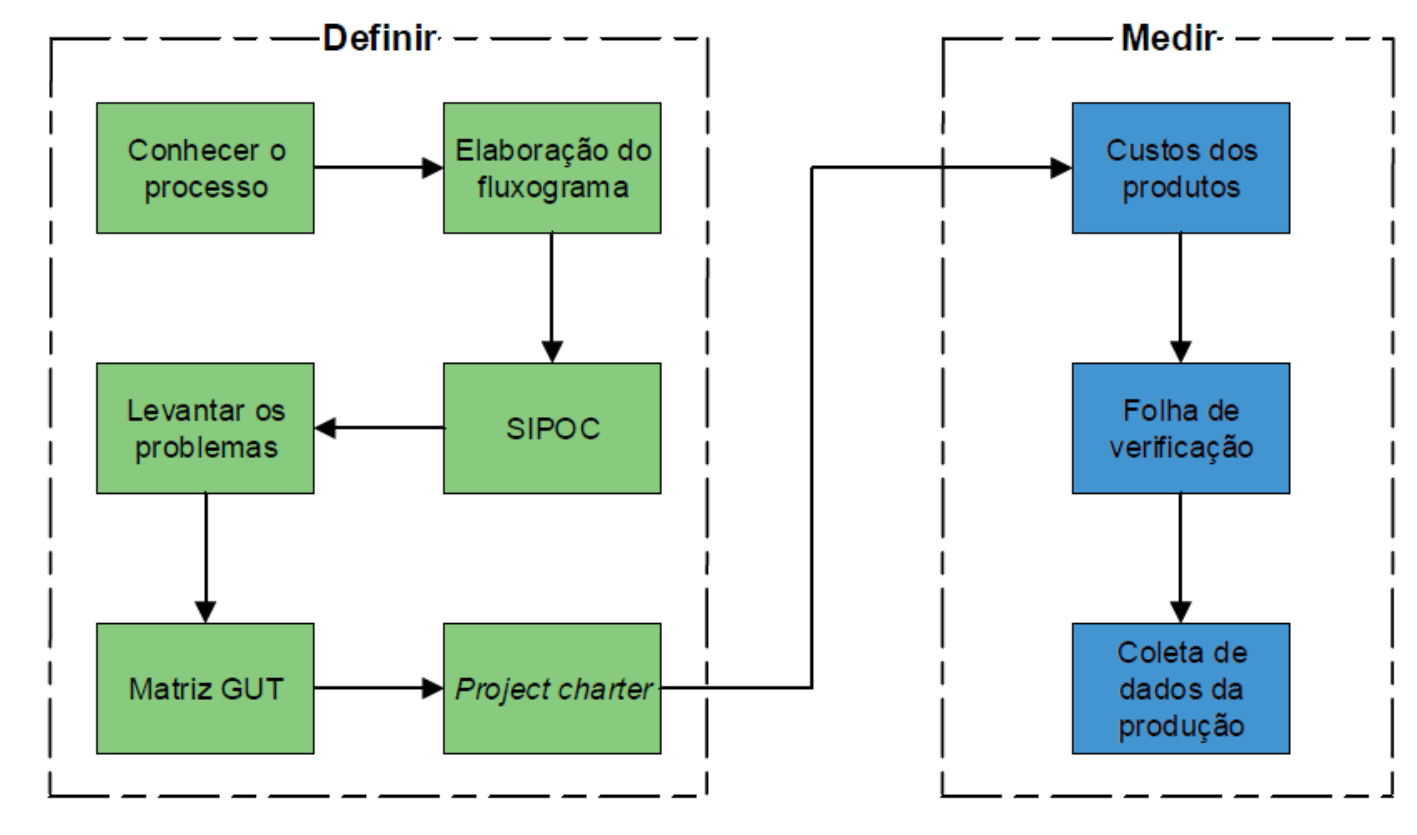

Fonte: Autoria própria (2020).

Utilizando de entrevistas não estruturadas com os responsáveis pela produção, foram levantados os problemas presentes no processo produtivo que podem afetar a qualidade. Após as entrevistas, houve a necessidade de priorizar os problemas encontrados, para que fosse definido o foco do trabalho, sendo utilizado para tal a matriz GUT. A elaboração do project charter foi a última etapa realizada na fase definir, descrevendo os envolvidos no projeto, os objetivos dele, resultados esperados e metas a serem alcançadas.

Após o término da fase definir, iniciou-se a fase medir, onde ocorreu a coleta de dados. Num primeiro momento os dados coletados estavam relacionados ao custo médio para produção dos produtos. Logo após, para que fosse possível mensurar as variáveis referentes ao problema, houve a necessidade de criar uma espécie de folha de verificação, encaminhada à produção e preenchida durante dois meses pelos operadores.

No procedimento de análise e interpretação dos dados, a fase incorporada da metodologia DMAIC é a analisar, conforme apresentado na Figura 2. Nesta fase foram utilizadas as seguintes ferramentas: Gráfico de Pareto, Histograma, aspetos financeiros, Nível Sigma, Diagrama de Ishikawa e 5W2H.

A partir dos dados coletados, o gráfico de Pareto foi utilizado para caracterização do setor de produção da empresa, apresentando as particularidades de cada linha de produção. Na sequência foram elaborados os histogramas, para verificar se os dados coletados apresentavam a característica de dados normais. A partir da combinação dos custos dos produtos e da utilização das linhas de produção foi realizada uma análise com relação aos aspectos financeiros. Adicionalmente, calculou-se o nível sigma do processo, com o intuito de verificar a situação atual por meio da escala sigma. 
Figura 2 - Procedimento de análise e interpretação dos dados

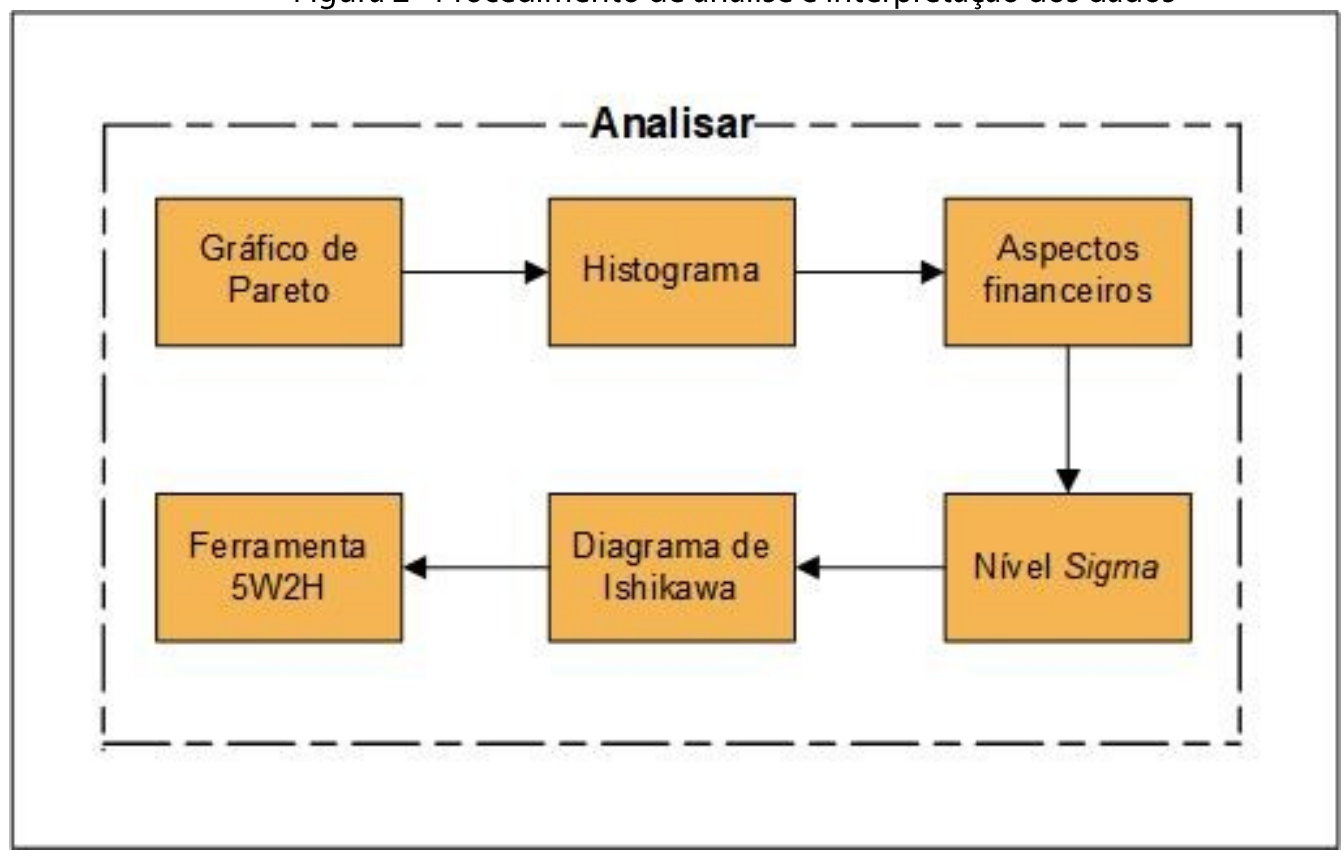

Fonte: Autoria própria (2020).

Como finalização desta fase, foram desenvolvidos o digrama de Ishikawa e a ferramenta $5 \mathrm{~W} 2 \mathrm{H}$, que tinham como objetivo identificar as possíveis causas raízes do problema do projeto e propor algumas soluções para resolução do problema, respectivamente.

\section{RESULTADOS E DISCUSSÕES}

Neste tópico será apresentado o desenvolvimento de cada etapa da metodologia DMAIC, abordando as análises realizadas e os resultados obtidos por meio da execução do trabalho.

\subsection{FASE DEFINIR}

A primeira etapa desenvolvida foi o procedimento de coleta de dados, onde iniciou-se a fase "definir" da metodologia DMAIC, nesta fase foram realizadas visitas à empresa que foi objeto de estudo do trabalho, o que possibilitou compreender melhor todas as etapas do processo produtivo, bem como analisar e levantar alguns pontos de possíveis melhorias. Uma das ferramentas utilizadas nesta fase foi o SIPOC, onde o processo foi desenhado de uma maneira macro, de modo a facilitar o entendimento do escopo, no qual são apresentados os fornecedores, entradas, saídas, clientes e o processo em si, como pode ser visualizado na Figura 3.

Através da ferramenta SIPOC e das visitas realizadas, identificaram-se as etapas do processo que apresentam problemas, ou seja, as etapas onde existem oportunidades de melhoria, sendo elas: a manipulação, mistura e envase. De acordo com cada etapa, foram elencadas algumas oportunidades de melhorias como: sobra de produto acabado; acondicionamento da matéria-prima; questões ergonômicas na manipulação; dificuldade na medição de água nos misturadores utilizados para a produção, entre outros. Com o objetivo de auxiliar na priorização dos problemas, utilizou-se a matriz GUT, onde foram listadas as oportunidades de melhoria e atribuídas notas à cada fator, considerando os problemas elencados 
anteriormente, logo, o problema escolhido para ser abordado foi aquele que resultou no maior índice, resultado da multiplicação entre gravidade, urgência e tendência.

Figura 3 - SIPOC do processo

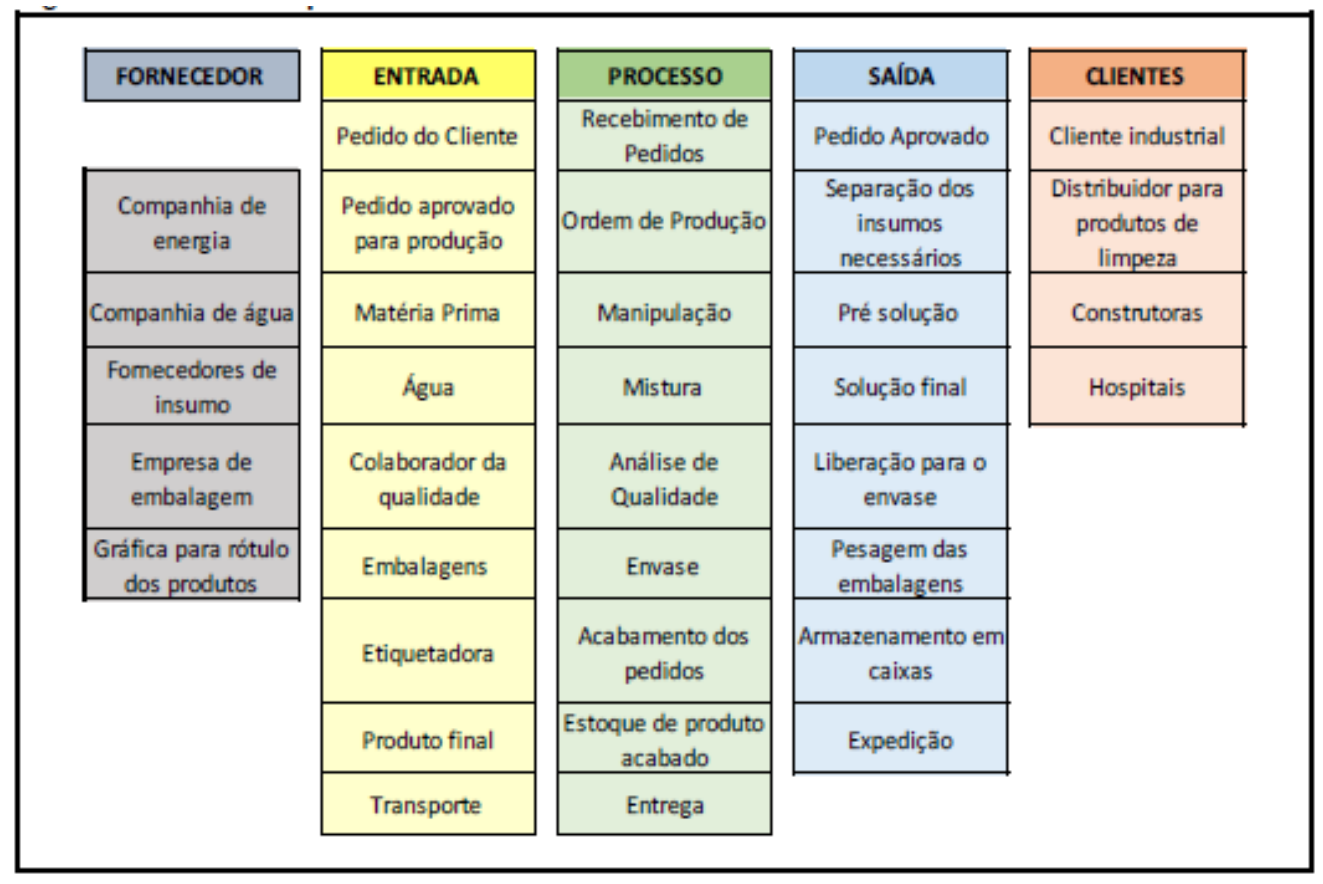

Fonte: Autoria própria (2020).

Sendo assim, o problema que resultou em um maior índice na matriz GUT diz respeito à dificuldade na medição de água dos misturadores. A água é a matéria prima presente em todos os produtos fabricados pela indústria química, portanto, sua correta medição pode impactar todos os produtos, levando a uma melhoria global.

Seguindo a metodologia proposta pelo trabalho, a próxima etapa diz respeito a elaborar o project charter, definindo o título do projeto, equipe responsável, meta a ser alcançada, entre outros assuntos pertinentes. Desta forma, elaborou-se o project charter com base no problema priorizado pela matriz GUT, e este pode ser visualizado no Quadro 1.

Quadro 1 - Project charter do trabalho

\begin{tabular}{|l|l|}
\hline \multicolumn{2}{|c|}{ Project Charter } \\
\hline Título do projeto & Implementação da metodologia Lean Six Sigma em uma indústria química \\
\hline $\begin{array}{l}\text { Data de abertura do } \\
\text { projeto }\end{array}$ & Agosto/2018 \\
\hline Cliente & Empresa química \\
\hline CTQ & Quantidade de produto acabado que sobrou (kg) da produção dos produtos \\
\hline Meta do projeto & Reduzir a sobra dos produtos ao menor índice possível, aproximando-se de 0\% \\
\hline Membros da equipe & $\begin{array}{l}\text { Alunos de Engenharia de Produção da UTFPR PG, Professora orientadora, } \\
\text { Colaboradores do setor de produção da empresa e diretores }\end{array}$ \\
\hline Benefícios esperados & $\begin{array}{l}\text { Redução de desperdícios, Diminuição de custos de produção, redução de } \\
\text { estoque de produto acabado, liberação de espaço físico }\end{array}$ \\
\hline
\end{tabular}

Fonte: Autoria própria (2020) 
Acredita-se que a medição de água está diretamente relacionada à sobra de produto acabado, uma vez que, para a produção de determinado produto, se for adicionada água nos misturadores além da quantidade necessária, ocorrerá a sobra da produção. Portanto, tratando o problema da medição de água, ocorrerá a redução da sobra da produção, sendo este aspecto considerado como objetivo do projeto.

\subsection{Fase medir}

A fase "Medir" é caracterizada pela coleta de dados, sendo que esta deve ser realizada de maneira que seja possível qualificar e quantificar o que foi definido como meta principal do projeto na fase "Definir". A meta estabelecida está relacionada a reduzir a sobra de produção ao menor índice possível, aproximandose de $0 \%$.

\subsubsection{Coleta de dados}

Foram coletados dados relacionados à questão financeira dos produtos, principalmente no que diz respeito ao custo médio que eles apresentam. Para isto foram disponibilizados pela empresa, por meio de seu sistema de gestão empresarial, a curva $A B C$ dos produtos produzidos, que considerava a quantidade produzida e o custo dos produtos, sendo possível o cálculo do custo médio. Esta curva $A B C$ considerou os produtos produzidos no período de 01 de janeiro de 2018 e 14 de novembro de 2018.

Após a definição da meta do projeto, fez-se necessário criar um banco de dados que considerasse a sobra dos produtos, pois a empresa não possuía um histórico com estes dados, logo, a equipe do projeto elaborou um documento com o auxílio do Microsoft Excep para que os funcionários anotassem as sobras ocorridas em cada produção. As anotações foram realizadas em uma folha de papel, uma espécie de folha de verificação, que ficava sob a responsabilidade dos funcionários da produção.

O documento disponibilizado para a empresa continha as seguintes informações: data da produção, nome do produto, quantidade solicitada, sobra de produção, quebra de produção, número da linha em que o produto foi feito e densidade do produto. Os termos sobra e quebra, são utilizados pela própria equipe de produção, sendo que a sobra corresponde à quantidade de produto produzida a mais que o solicitado e a quebra refere-se à quantidade de produto que faltou ser produzida.

Foi estabelecido que a coleta dos dados teria uma duração de dois meses, para que se tivesse uma amostra representativa. Desta maneira, a coleta de dados se iniciou no dia 20 de novembro de 2018 e teve fim em 04 de fevereiro de 2019, totalizando 8 semanas de dados coletados. A Tabela 1 contém uma síntese dos dados coletados durante este período.

Tabela 1 - Síntese de dados coletados

\begin{tabular}{cccc}
\hline Síntese dos dados coletados & & \\
\hline $\begin{array}{c}\text { Linha de } \\
\text { produção }\end{array}$ & $\begin{array}{c}\text { Quantidade de vezes } \\
\text { que a linha foi } \\
\text { utilizada }\end{array}$ & $\begin{array}{c}\text { Quantidade de vezes que } \\
\text { houve sobra }\end{array}$ & $\begin{array}{c}\text { Total de sobra em } \\
\text { cada linha (Kg) }\end{array}$ \\
\hline Linha Brute & 157 & 21 & 101,22 \\
Linha 1 & 35 & 8 & 119,42 \\
Linha 6 & 10 & 2 & 45,02 \\
Linha 5 & 2 & 1 & 19,5 \\
Jarra & 2 & 0 & 0 \\
Linha 2 & 1 & 0 & 0 \\
\hline
\end{tabular}

Fonte: Autoria própria (2020). 
No período mencionado, a empresa teve um total de 207 produtos produzidos, dos quais 32 geraram sobras, representando uma quantia de $285,16 \mathrm{Kg}$ de produto acabado. Já a quebra de produção foi observada em apenas 3 produtos, totalizando $34,62 \mathrm{Kg}$.

A fim de analisar as sobras de produção, os dados foram estratificados de acordo com as linhas de produção da empresa, sendo que durante o período de coleta, a empresa fez uso de 6 linhas de produção, conforme pode ser observado na Tabela 1.

\subsection{Fase Analisar}

A fase "analisar" teve por objetivo identificar as causas raízes do problema, e as fontes de desperdício, alinhado a meta do projeto, as análises foram feitas em relação às sobras de produção. Os dados coletados foram analisados com o auxílio do gráfico de Pareto, que permitiu observar quais as linhas mais utilizadas e aquelas que apresentavam mais sobra e, portanto, as que deveriam ser priorizadas no tratamento do problema, como mostra a Figura 4.

Como pode ser observado na Figura 4, a Linha Brute foi a mais utilizada para a fabricação dos produtos, correspondendo a $75,85 \%$ da produção no período em que os dados foram coletados. Considerando a Linha Brute juntamente com a Linha 1, que foi a segunda mais utilizada, estas correspondem a 92,75\% da produção do período.

Cada linha de produção possui sua especificidade, com relação ao volume de produção, pois na Linha Brute, por exemplo, a produção apresentou uma média de $73,19 \mathrm{Kg}$, sendo $500 \mathrm{Kg}$ o valor máximo encontrado e $5 \mathrm{Kg}$ a menor demanda para esta linha. Já a Linha 1, teve como característica a fabricação de produtos de $290,6 \mathrm{Kg}$ em média, sendo a maior produção de $679 \mathrm{Kg}$ e a menor $120 \mathrm{Kg}$, sendo que esta mesma análise se estende para as demais linhas de produção.

Figura 4 - Utilização das linhas de produção

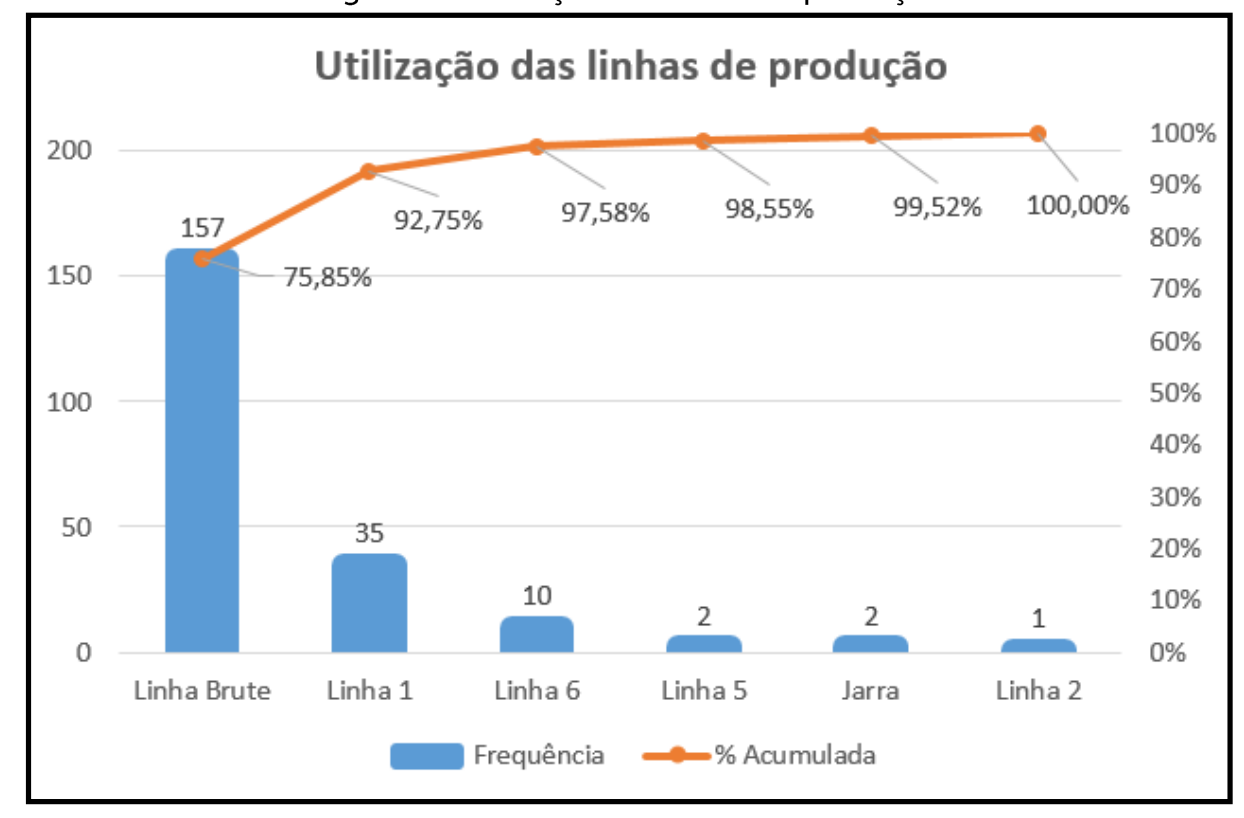

Fonte: Autoria própria (2020). 
Diante dessas características, os dados foram analisados de uma outra perspectiva, desta vez considerando a frequência relativa, tomando como base as vezes que a linha de produção foi utilizada e as vezes que esta apresentou sobras, construindo-se a Tabela 2.

Tabela 2 - Sobras: frequência relativa

\begin{tabular}{ccccc}
\hline Linha de & $\begin{array}{c}\text { Quantidade de } \\
\text { vezes que a } \\
\text { produção } \\
\text { linha foi } \\
\text { utilizada }\end{array}$ & $\begin{array}{c}\text { Quantidade de } \\
\text { vezes que } \\
\text { houve sobra }\end{array}$ & $\begin{array}{c}\text { Frequência } \\
\text { relativa }\end{array}$ & $\begin{array}{c}\text { Total de sobra em } \\
\text { cada linha (Kg) }\end{array}$ \\
\hline Linha 5 & 2 & 1 & $50,00 \%$ & 19,5 \\
Linha 1 & 35 & 8 & $22,86 \%$ & 119,42 \\
Linha 6 & 10 & 2 & $20,00 \%$ & 45,02 \\
Linha Brute & 157 & 21 & $13,38 \%$ & 101,215 \\
\hline
\end{tabular}

Fonte: Autoria própria (2020)

A frequência relativa mostra em porcentagem quantas vezes houve falha (sobra) do produto naquela linha de produção, desta maneira, considerando a Linha 5, que foi utilizada para produção apenas 2 vezes, das quais uma delas exibiu sobra, tem-se que $50 \%$ dos produtos feitos naquela linha apresentaram sobras. A mesma lógica se aplica às demais linhas de produção contidas na Tabela 2.

Desta maneira, considerando como prioritário o maior valor percentual, a ordenação observada no gráfico de Pareto se inverte na Tabela 2, apresentando, nesta ordem, a Linha 5, Linha 1, Linha 6 e Linha Brute como prioridade no tratamento do problema. Importante destacar que na Tabela 2, a Linha 2 e a Jarra não aparecem porque não apresentaram sobras quando utilizadas.

\subsubsection{Análise financeira}

Adicionalmente, foram analisados os custos relativos às sobras de produção. Os cálculos referentes aos aspectos financeiros foram realizados da seguinte maneira: foram verificados quais produtos apresentaram sobra em determinada Linha de produção e em que quantidade, sendo tal quantidade multiplicada pelo custo médio, em reais, obtido pela curva $A B C$ fornecida pela empresa, por meio de seu sistema de gestão empresarial. Os custos foram somados e atribuídos a cada uma das linhas onde se verificou a sobra. A Tabela 3 apresenta os dados de acordo com o custo das sobras.

A Linha 1 foi responsável pela produção de $10.171 \mathrm{Kg}$ de produtos e foi a linha que resultou em maior sobra, sendo 119,42 Kg. Monetariamente esta quantidade representa R\$433,20. Já a Linha Brute foi a que apresentou um total $11.491 \mathrm{Kg}$ produzidos, com sobra de $101,22 \mathrm{Kg}$, que corresponde ao valor de $\mathrm{R} \$$ 304,59 .

A Linha 5 apesar de ter sido utilizada apenas 2 vezes, produziu $1.600 \mathrm{Kg}$, com 19,5 Kg de sobra, 0 que resultou em $\mathrm{R} \$ 90,87$. A Linha 6 produziu $5.860 \mathrm{Kg}$ de produto, apresentando 45,02 $\mathrm{Kg}$ de sobra resultando em um valor de $\mathrm{R} \$ 77,09$. No período de 40 dias, considerando as seis linhas de produção, a empresa produziu um total de $29.524 \mathrm{Kg}$ de produtos, com total de sobra de $285,16 \mathrm{Kg}$, que financeiramente representa $\mathrm{R} \$ 905,75$. 
Tabela 3 - Análise dos custos da sobra

\begin{tabular}{ccccc}
\hline \multicolumn{5}{c}{ Custos das sobras } \\
\hline $\begin{array}{c}\text { Linha de } \\
\text { produção }\end{array}$ & $\begin{array}{c}\text { Quantidade de } \\
\text { vezes que a linha } \\
\text { foi utilizada }\end{array}$ & $\begin{array}{c}\text { Total produzido } \\
(\mathrm{kg})\end{array}$ & $\begin{array}{c}\text { Total de } \\
\text { Sobra }(\mathrm{kg})\end{array}$ & Custo total (R\$) \\
\hline Linha 1 & 35 & 10.171 & 119,42 & $\mathrm{R} \$ 433,20$ \\
Linha Brute & 157 & 11.491 & 101,22 & $\mathrm{R} \$ 304,59$ \\
Linha 5 & 2 & 1.600 & 19,5 & $\mathrm{R} \$ 90,87$ \\
Linha 6 & 10 & 5.860 & 45,02 & $\mathrm{R} \$ 77,09$ \\
Total & 204 & 29.122 & 285,16 & $\mathrm{R} \$ 905,75$ \\
\hline
\end{tabular}

Fonte: Autoria própria (2020).

Como os dados obtidos correspondem a dois meses de produção, pode-se inferir que, se o comportamento da produção se verificasse constante ao longo do ano, isto é, se as mesmas características e os mesmos produtos continuassem a sobrar no decorrer do ano, basta multiplicar o custo total obtido por 6 para se obter o custo das sobras durante o ano. Sendo assim, o custo anual das sobras seria de $\mathrm{R} \$ 5.434,50$, o que é equivalente à produção de $3.313,7 \mathrm{Kg}$ do produto de maior demanda que a empresa possui atualmente.

\subsubsection{Nível Sigma}

Para que fosse possível calcular o nível sigma do processo, foram levados em consideração os defeitos relacionados à sobra. Com isso, para fosse possível calcular o DPMO, foi necessário determinar os defeitos para a oportunidade, ou seja, quais são as variáveis que interferem na quantidade de sobra dos produtos. As variáveis que poderiam ocasionar sobra são: viscosidade do produto, quantidade de água nos misturadores, balança sem precisão, densidade do produto e quantidade de matéria prima. Estas variáveis foram definidas juntamente com os colaboradores da empresa. Desta forma, foram identificados cinco defeitos para oportunidade.

Com base na estratificação dos dados, constatou-se que, de um total de 207 produtos produzidos, 172 foram considerados conformes e 35 não conformes, ou seja, 35 produtos apresentaram sobra na produção. Para o cálculo do nível sigma do processo, determinou-se primeiramente o DPO, que consiste em defeitos por oportunidade, e em seguida o DPMO, que apresenta o número de defeitos por milhão de oportunidades. Os cálculos destes itens foram feitos conforme apresenta as equações 1 e 2 .

$$
\begin{aligned}
\text { DPO } & =\frac{172}{(207 * 5)}=0,166184 \\
\text { DPMO } & =0,166184^{*} 10^{6}=166.184
\end{aligned}
$$

A partir do cálculo do DPO e DPMO pode-se concluir sobre o nível sigma do processo, sendo que a Tabela 4 apresenta um compilado dos dados utilizados e dos resultados obtidos através dos cálculos. 
Tabela 4 - Nível Sigma atual

\begin{tabular}{ll}
\hline Nível Sigma & \\
\hline Total produzido & 207 \\
Itens Conformes & 172 \\
Itens Não-Conformes & 35 \\
DPO & 0,166184 \\
DPMO & 166.184 \\
Nível Sigma & 2,45 \\
\hline
\end{tabular}

Fonte: Autoria própria (2020).

Com base nos resultados conclui-se que, no processo em estudo, a cada um milhão de produtos produzidos, há uma probabilidade de 166.184 produtos apresentarem sobra ou quebra. Para identificar o nível sigma do processo, utilizou-se a tabela de conversão para escala Sigma, sendo o valor correspondente a 2,45 desvios padrão. Visto que o valor máximo para a escala sigma é de 6 desvios padrão, pode-se dizer que há oportunidade para melhoria do processo, no que diz respeito à sua estabilização, considerando o nível sigma.

\subsubsection{Diagrama de Ishikawa}

Durante o período da coleta dos dados, foi possível conhecer a maneira de trabalho da empresa e realizar um brainstorming com a equipe da produção, onde verificou-se as possíveis causas da elevada quantidade de sobra de produto acabado, conforme apresenta a Figura 5.

Após a análise, foram identificadas quatro possíveis causas relacionadas a sobra dos produtos. Primeiramente em relação ao maquinário da empresa, elencaram-se duas principais causas, sendo a falta de precisão na balança utilizada e a infraestrutura no envase. Em relação à balança, a empresa utiliza com frequência balanças em seu processo produtivo, sendo que existem dois momentos que podem afetar na sobra: na preparação da matéria prima e no envase.

O processo de envase da empresa é totalmente manual, sendo que, para cada tipo de produto, os colaboradores precisam encontrar a melhor forma de envase. Contudo, esta falta de infraestrutura no envase prejudica o andamento do processo, podendo inclusive causar fadiga nos colaboradores, pois em casos onde o produto é comercializado em forma de gel, por exemplo, encontra-se dificuldade no envase, devido ao seu estado físico.

Em relação ao método, a empresa não possui um processo eficiente para medição da quantidade de água inserida nos misturadores, pois atualmente a medição ocorre com um varão de madeira, no qual existem algumas marcações apontando a quantidade de litros de água já inserida no misturador, sendo que este procedimento só ocorre na Linha 1.

Em relação à mão de obra, verifica-se que não há um padrão na maneira que o colaborador insere a quantidade de água nos misturadores, pois certas vezes utiliza-se uma mangueira para esta finalidade e outras vezes utiliza-se um contêiner com capacidade de 1.000 litros para que seja feita a medição da quantidade de água, o que depende da linha de produção com a qual se está trabalhando. Tais práticas podem ocasionar superprodução e retrabalho, caso seja inserida uma quantidade de água superior a necessária. 
Figura 5 - Diagrama de Ishikawa

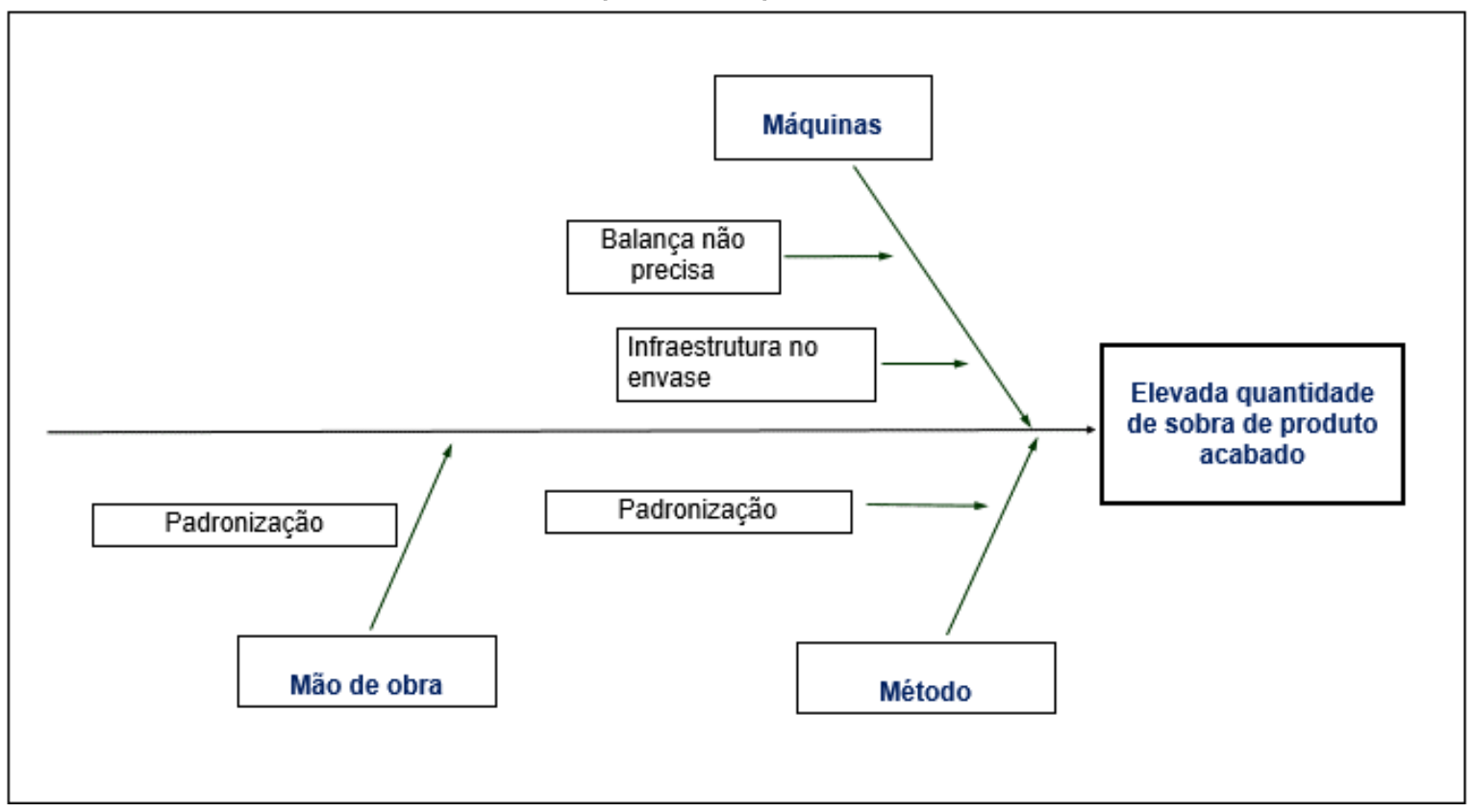

Fonte: Autoria própria (2020).

\subsubsection{Ferramenta $5 \mathrm{~W} 2 \mathrm{H}$}

Em vista do que foi apresentado anteriormente, foi elaborada a ferramenta $5 \mathrm{~W} 2 \mathrm{H}$ para visualizar melhor as sugestões de melhoria que podem ser implementadas no processo produtivo. Tal ferramenta pode ser visualizada no Quadro 2.

Com relação à ineficiência na medição da quantidade de água colocada nos misturadores, foram levantadas duas sugestões: a adoção de um hidrômetro e a elaboração de um aparato que se utiliza do princípio dos vasos comunicantes. O hidrômetro seria adotado mais especificamente no misturador presente na Linha 1, pois este é o misturador que possivelmente se adequará a esta sugestão.

Importante mencionar que a Linha 1 foi responsável, no período de dois meses, por cerca de 16,9\% da produção dos produtos, sendo a segunda Linha mais utilizada na empresa, aquela que apresentou maior quantidade de sobra de produtos em quilogramas e cerca de $22,86 \%$ das vezes que foi utilizada, apresentou sobra de produtos.

A fim de verificar a viabilidade financeira do hidrômetro, realizou-se uma pesquisa sobre o preço deste, sendo que o preço médio de um hidrômetro que se adequaria às características presentes na Linha 1 , é de R\$2.013. Desta maneira, pode-se inferir que, se a empresa realizar o investimento, em torno de um ano conseguirá pagá-lo e reduzirá a sobra de produto acabado.

A outra solução proposta, e que talvez seja mais adequada para outras Linhas de produção, como a 5 e a 6 , é a utilização do princípio dos vasos comunicantes. Devido às características físicas dos misturadores das Linhas 5 e 6, a inserção de um hidrômetro seja muito mais complexa do que a aplicação do princípio dos vasos comunicantes. Para tal, seria necessária uma mangueira transparente fixada na posição vertical, um engate rápido para fazer a ligação entre a mangueira e o misturador e um pequeno painel de madeira para realizar as marcações do volume de água. Para tal implementação a empresa investiria em média $R \$ 60$, o que é uma solução relativamente barata, em relação ao hidrômetro.

Também foi verificada certa dificuldade na etapa de envase por parte dos operadores, no que diz respeito aos utensílios disponíveis para realizar esta tarefa, geralmente quando o produto possui um aspecto de gel ou pastoso. Para esta situação, os operadores precisam improvisar maneiras de se realizar o 
envase, o que acaba contribuindo para que haja sobra de produto nos recipientes em que este foi acondicionado.

Em vista disso, a sugestão é investir em um maquinário que possua o princípio da alavanca mecânica, pois assim facilitaria o envase de produtos que possuem aspecto em gel ou pastoso. Foi realizada uma pesquisa de preços de equipamentos que poderiam auxiliar neste processo, sendo que o custo inicial seria em média de $\mathrm{R} \$ 5.450$. A longo prazo o investimento contribuiria para a atividade de envase dos operadores e reduziria as sobras de produto, no caso de um produto em gel.

No caso das balanças desgastadas, a sugestão seria realizar a troca delas, de acordo com a necessidade de cada estação de trabalho e da atividade que está sendo desenvolvida. As balanças são ferramentas de extrema importância para o processo produtivo da empresa, com isso, é importante que se faça um estudo financeiro para que ocorra a substituição das balanças, evitando que ocorram desperdícios devido à falta de precisão delas.

A balança tipo 1, que consta no $5 \mathrm{~W} 2 \mathrm{H}$, diz respeito a uma balança de bancada com capacidade de $15 \mathrm{Kg}$ e $2 \mathrm{~g}$ de escala de medição, que seria empregada na etapa do envase, em que é necessário aferir a embalagem preenchida com o produto químico que foi produzido. O custo médio deste tipo de balança é de $R \$ 580$. Já o tipo 2, diz respeito a uma balança com capacidade de $6 \mathrm{Kg}$ e $1 \mathrm{~g}$ de escala de medição, cujo custo médio é de $\mathrm{R} \$ 945$, que seria empregada na etapa da mistura para aferir os insumos. A balança móvel digital é o tipo 3, que apresenta um custo médio de $\mathrm{R} \$ 2.675$ e capacidade para $300 \mathrm{Kg}$, sendo empregada também na etapa do envase, mas seria mais voltada à produção de grandes quantidades de produto, que necessita ser envasado em um recipiente de grandes dimensões. 
Quadro 2 - Preenchimento da ferramenta 5W2H

\begin{tabular}{|c|c|c|c|c|c|c|c|}
\hline Hipótese & O que fazer? & Por quê? & Onde? & Como? & Quem? & Quando? & Quanto? \\
\hline \multirow{2}{*}{$\begin{array}{l}\text { Ineficiência } \\
\text { na medição } \\
\text { da } \\
\text { quantidade } \\
\text { de água } \\
\text { colocada nos } \\
\text { misturadores. }\end{array}$} & $\begin{array}{l}\text { Instalar hidrômetro } \\
\text { na entrada de água } \\
\text { dos reatores. }\end{array}$ & $\begin{array}{l}\text { O hidrômetro é } \\
\text { capaz de medir } \\
\text { com maior precisão } \\
\text { a quantidade de } \\
\text { água inserida. }\end{array}$ & $\begin{array}{l}\text { Primeiramente } \\
\text { no misturador } \\
\text { da Linha } 1 .\end{array}$ & $\begin{array}{l}\text { Realizar um estudo de } \\
\text { viabilidade financeira } \\
\text { sobre a instalação do } \\
\text { hidrômetro e adquirir } \\
\text { um desses } \\
\text { equipamentos. }\end{array}$ & $\begin{array}{l}\text { Responsável pela } \\
\text { produção e } \\
\text { responsável pelo } \\
\text { financeiro. }\end{array}$ & $\begin{array}{l}\text { A partir de } \\
\text { maio de } 2019 .\end{array}$ & $\begin{array}{l}\text { Em média } \\
\mathrm{R} \$ 2.013,00 .\end{array}$ \\
\hline & $\begin{array}{l}\text { Utilizar o princípio } \\
\text { dos vasos } \\
\text { comunicantes para } \\
\text { medição da água. }\end{array}$ & $\begin{array}{l}\text { É uma opção } \\
\text { relativamente } \\
\text { barata e que pode } \\
\text { contribuir para } \\
\text { diminuir as sobras. }\end{array}$ & $\begin{array}{l}\text { Nos } \\
\text { misturadores } \\
\text { das Linhas } 5 \text { e } \\
6 \text {, devido as } \\
\text { suas } \\
\text { características } \\
\text { físicas. }\end{array}$ & $\begin{array}{l}\text { Utilizar uma mangueira, } \\
\text { onde será feita uma } \\
\text { escala que meça o } \\
\text { volume de água, } \\
\text { acoplada à saída do } \\
\text { misturador, que é a } \\
\text { parte destinada ao } \\
\text { envase. }\end{array}$ & $\begin{array}{l}\text { Responsável pela } \\
\text { produção e } \\
\text { operadores da } \\
\text { produção. }\end{array}$ & $\begin{array}{l}\text { A partir de } \\
\text { maio de } 2019 .\end{array}$ & $\begin{array}{l}\text { Em média } \\
\mathrm{R} \$ 60,00 \text {. }\end{array}$ \\
\hline $\begin{array}{l}\text { Falta de } \\
\text { estrutura no } \\
\text { processo de } \\
\text { envase. }\end{array}$ & $\begin{array}{l}\text { Verificar } \\
\text { equipamentos mais } \\
\text { adequados para o } \\
\text { envase. }\end{array}$ & $\begin{array}{l}\text { Elimina a } \\
\text { necessidade de } \\
\text { improviso, por } \\
\text { parte dos } \\
\text { operadores, no } \\
\text { envase dos } \\
\text { produtos. }\end{array}$ & $\begin{array}{l}\text { Na etapa de } \\
\text { envase. }\end{array}$ & $\begin{array}{l}\text { No caso do envase de } \\
\text { produtos em gel, pode- } \\
\text { se utilizar um } \\
\text { equipamento que utilize } \\
\text { o princípio da alavanca } \\
\text { mecânica, presente no } \\
\text { cotidiano das pessoas } \\
\text { em um amassador em } \\
\text { batatas, por exemplo. }\end{array}$ & $\begin{array}{l}\text { Responsável pela } \\
\text { produção e } \\
\text { responsável pelo } \\
\text { financeiro. }\end{array}$ & $\begin{array}{l}\text { A partir de } \\
\text { maio de } 2019 .\end{array}$ & $\begin{array}{l}\text { Em média } \\
\mathrm{R} \$ 5.450,00 .\end{array}$ \\
\hline $\begin{array}{l}\text { Utilização de } \\
\text { balanças } \\
\text { desgastadas. }\end{array}$ & $\begin{array}{l}\text { Trocar as balanças } \\
\text { que apresentam } \\
\text { desgastes. }\end{array}$ & $\begin{array}{l}\text { Elimina erros de } \\
\text { imprecisão, } \\
\text { auxiliando na } \\
\text { redução da sobra. }\end{array}$ & $\begin{array}{l}\text { Nas etapas que } \\
\text { utilizem de } \\
\text { balança }\end{array}$ & Adquirir novas balanças. & $\begin{array}{l}\text { Responsável pela } \\
\text { produção e } \\
\text { responsável pelo } \\
\text { financeiro. }\end{array}$ & $\begin{array}{l}\text { A partir de } \\
\text { maio de } 2019 .\end{array}$ & $\begin{array}{l}\text { 1. Em média } \\
\mathrm{R} \$ 580,00 \text {. } \\
\text { 2. Em média } \\
\mathrm{R} \$ 945,00 \text {. } \\
\text { 3. Em média } \\
\mathrm{R} \$ 2.675,00 \text {. }\end{array}$ \\
\hline
\end{tabular}

Fonte: Autoria própria (2020). 


\subsection{Considerações em relação aos resultados}

Com relação à aplicação das ações, que correspondem às fases melhorar e controlar da metodologia DMAIC, o plano de ação é apresentado na ferramenta $5 \mathrm{~W} 2 \mathrm{H}$. Tais propostas serão implementadas caso a empresa julgue que estas são pertinentes e adequadas ao processo produtivo atual, em termos de aplicabilidade, custo e retorno que pode trazer aos resultados empresariais, cabendo a ela sua aplicação e controle.

Para realizar o controle das ações implementadas, verificando se a medida adotada foi efetiva ou não, pode-se adotar a folha de verificação criada para coleta de dados e realizar a coleta durante um determinado período após a adoção da medida. Na sequência, os dados devem ser analisados, de maneira que seja possível verificar se houve ou não uma melhoria no aspecto de sobras dos produtos, ou seja, quanto menos produtos sobrarem, melhor, portanto, houve uma melhoria caso tenha sobrado menos produtos que antes. Esta análise pode ser feita pela comparação entre a quantidade média de sobras dos produtos (em quilograma), antes da aplicação da medida e depois da implementação da sugestão.

Por fim, realizando uma análise para determinar a capacidade produtiva que a empresa utiliza hoje para suas atividades, observa-se que apenas $13 \%$ de sua capacidade atual instalada é utilizada. Esta análise foi feita a partir da soma da capacidade total em quilograma de cada misturador, levando em consideração um dia de produção. Desta maneira, a empresa pode produzir $6.102 \mathrm{Kg}$ de produto diariamente, de acordo com a capacidade instalada. A partir dos dados coletados pela folha de verificação, calculou-se a média de produção para o dia, resultando em um valor de 766,42 Kg. Este valor foi dividido pela capacidade diária, o que resultou em um valor de aproximadamente $13 \%$.

Desta maneira, pode-se inferir que se hoje a empresa opera com $13 \%$ da capacidade e ocorre o problema de sobras, que resulta em um valor anual estimado de $\mathrm{R} \$ 5.434,50$, e ela tem o plano de expandir suas atividades para atender a todo o território nacional, sua demanda por produtos tende a aumentar, logo, se o problema não for tratado, este valor anual estimado para as sobras também tende a aumentar.

\section{CONSIDERAÇÕES FINAIS}

Diante das análises realizadas, pode-se inferir que o objetivo geral e os objetivos específicos do trabalho foram atingidos, bem como foi possível a aplicação de ferramentas da qualidade em um contexto industrial considerando dados reais.

O objetivo geral do trabalho relaciona-se a propor realizar um estudo da implementação da metodologia Lean Six Sigma, em uma indústria do setor de fabricação de produtos químicos. Para tal, foram implementadas melhorias no processo produtivo de uma indústria do setor de fabricação de produtos químicos, o que foi atingido por meio da utilização da metodologia DMAIC e da utilização de princípios do Lean Manufacturing, como a identificação e eliminação de desperdícios, sendo, neste caso, a superprodução.

O trabalho seguiu a metodologia DMAIC, sendo que dela foram desenvolvidas as etapas definir, medir e analisar, cabendo a implementação e o controle das ações adotadas à empresa estudada. Desta maneira, houve a aplicação parcial da metodologia DMAIC, foram utilizadas ferramentas em cada fase da metodologia DMAIC, que conduziu o presente trabalho.

O mapeamento do processo produtivo da indústria foi a primeira atividade desenvolvida, onde foram identificadas as etapas de produção, os procedimentos que ocorrem em cada uma delas e quais são os recursos requeridos por cada etapa. Para esta situação utilizou-se de um fluxograma do processo e da ferramenta SIPOC, utilizada no Six Sigma.

Após a observação do processo, foram identificadas as oportunidades de melhoria presentes nele, bem como as características existentes que podem influenciar na sua qualidade. Para que fosse dado sequência ao trabalho, utilizou-se a matriz GUT como ferramenta para priorizar uma oportunidade de melhoria, que, por sua vez, funcionou como foco principal para o trabalho.

$\mathrm{Na}$ fase medir, presente na metodologia DMAIC, ocorreu a coleta de dados referentes ao processo produtivo, o que foi realizado com o auxílio de uma folha de verificação, sendo que tal coleta teve a duração de dois meses. Também foram disponibilizados dados referentes à curva $A B C$ dos produtos fabricados pela 
empresa, bem como o custo médio destes produtos, o que foi fornecido por meio do software de gestão da indústria.

Já na análise dos dados coletados, foi possível verificar o comportamento dos dados coletados, a utilização das linhas de produção, quais das linhas apresentam maior quantidade de sobras, qual o custo médio das sobras para a empresa, uma estimativa do custo anual das sobras e qual o nível sigma atual do processo. Tais análises foram feitas com base nas ferramentas do gráfico de Pareto, DPO, DPMO e escala sigma.

As propostas de melhorias para o processo analisado foram auxiliadas pela ferramenta do diagrama de Ishikawa e 5W2H, que tornam toda a análise mais visual e condensada no mesmo lugar, facilitando o entendimento das ações propostas.

O desenvolvimento do projeto trouxe contribuições para o meio acadêmico e para a empresa. Em relação ao meio acadêmico pode-se concluir que a aplicação da metodologia Lean Six Sigma é possível em uma indústria do setor químico, pois, apesar das limitações do trabalho, os resultados alcançados foram obtidos através de ferramentas e princípios de cada metodologia, além de verificar que a fusão entre o Lean e o Six Sigma possibilita uma visão mais crítica sobre o ambiente estudado.

Para a empresa, toda a análise feita em seu processo produtivo foi um ganho, pois através dela foi possível levantar pontos de melhoria e documentá-los, funcionando como um guia para intervenções futuras, baseado em um estudo específico para a realidade apresentada. Desta maneira, as sugestões de melhoria vêm para aumentar a qualidade do seu processo, sendo um aspecto que deve ser considerado, uma vez que isso pode trazer ganhos financeiros para ela e aumento na eficiência de suas operações.

Uma das sugestões para trabalhos futuros, diz respeito a realizar uma coleta de dados referente a quantidade de água inserida nos misturadores, ou seja, a cada produção deve-se comparar a quantidade de água que deveria ser inserida e a quantidade efetivamente adicionada nos misturadores. Com este dado será possível analisar e verificar se o sistema de medição da empresa está comprometido. Outra sugestão, seria a manipulação dos dados através de modelagem matemática utilizando pesquisa operacional, onde seria possível realizar diversas análises em relação a receita, custos, desperdícios, variáveis que mais interferem no processo, entre outros.

\section{REFERÊNCIAS}

ABIQUIM (Associação Brasileira da Indústria Química). 0 desempenho da indústria química em 2017. [2017]. Disponível em:

https://abiquim.org.br/uploads/guias_estudos/desempenho_industria_quimica_2017.pdf. Acesso em: 02 maio 2018.

CARVALHO, Marly Monteiro; PALADINI, Edson Pacheco. Gestão da qualidade: teoria e casos. 2. ed. Rio de Janeiro, RJ: Elsevier; Campus, 2012.

CHIROLI, Daiane Maria De Genaro et al. Um estudo sobre os custos da qualidade em uma empresa metal mecânica. Espacios, v. 37, p.19, 2016. Disponível em:

https://www.revistaespacios.com/a16v37n04/16370420.html. Acesso em: 21 set. 2019.

CONCEIÇÃO, Rodrigo Subirá et al. Lean six sigma: implementation of improvements to the industrial cost management. Independent Journal of Management \& Production, v. 10, p. 2023-2045, 2019. DOI: http://dx.doi.org/10.14807/ijmp.v10i6.996. Disponível em:

http://www.ijmp.jor.br/index.php/ijmp/article/view/996/1228. Acesso em: 03 dez. 2019.

DROHOMERETSKI Everton et al. Lean, Six Sigma and Lean Six Sigma: an analysis based on operations strategy, International Journal of Production Research, v. 52, n. 3, p. 804-824, 2014. DOI

10.1080/00207543.2013.842015. Disponível em:

https://www.tandfonline.com/doi/full/10.1080/00207543.2013.842015. Acesso em: 19 fev. 2020.

MARTINELLI, Fernando B. Gestão da Qualidade Total. Rio de Janeiro: Fundação Biblioteca Nacional, 2009. 
MOREIRA, Rafael; ARBACHE, Jorge. Os serviços e a indústria química . Disponível em: https://economiadeservicos.com/2016/12/19/os-servicos-na-industria-quimica/\#comments. Acesso em: 02 maio 2018.

PEPPER, M. P. J.; SPEDDING, T. A. The evolution of lean Six Sigma. International Journal of Quality and Reliability Management, v. 27, n. 2, p. 138-155, 2010. DOI 10.1108/02656711011014276. Disponível em: https://www.emerald.com/insight/content/doi/10.1108/02656711011014276/full/html. Acesso em: $12 \mathrm{dez}$. 2019.

RAVAL, S. J.; KANT, R.; SHANKAR, R. Revealing research trends and themes in 89 Lean Six Sigma: from 2000 to 2016. International Journal of Lean Six Sigma, v. 9, n. 3, p. 399-443, 2018. DOI:10.1108/IJLSS-03-2017-0021. Disponível em: https://www.emerald.com/insight/content/doi/10.1108/IJLSS-03-20170021/full/html?skipTracking=true. Acesso em: 19 fev. 2020.

SAKUMOTO, S. M.; DE GENARO CHIROLI, D. M.; DZULINSKI, A. C. Using Lean Six Sigma to Increase Efficiency of a Grain Receipt Process of a Brazilian Agroindustry Cooperative. American Journal of Engineering and Applied Sciences, v. 12, p. 214.226, 2019. DOI: 10.3844/ajeassp.2019.214.226. Disponível em: https://thescipub.com/abstract/10.3844/ajeassp.2019.214.226. Acesso em: 20 jun. 2019.

SALAH, S.; RAHIM, A.; CARRETERO, J. A. The integration of Six Sigma and lean management. International Journal of Lean Six Sigma, v. 1, n. 3, p. 249-274, 2010.

SABA E SILVA, Guilherme; DE GENARO CHIROLI, Daiane Maria de. Lean manufacturing: ações de melhorias em empresa metalmecânica. Navus - Revista de Gestão e Tecnologia, Florianópolis, v. 10, p. 01-13, jan. 2020. ISSN 2237-4558. Disponível em: http://navus.sc.senac.br/index.php/navus/article/view/996. Acesso em: 19 feb. 2020. doi:https://doi.org/10.22279/navus.2020.v10.p01-13.996.

SNEE, R. D. Lean Six Sigma - getting better all the time. International Journal of Lean Six Sigma, v. 1, n. 1, p. 9-29, 2010.

STAATSA, B. R., D. J. Brunnerb, and D. M. Upton. Lean Principles, Learning, and Knowledge Work: Evidence from a Software Services Provider. Journal of Operations Management, n. 29, p. 376-390, 2011.

WHEELER, D.J. The Six Sigma Practitioner's Guide to Data Analysis. Tennessee:SPC Press Knoxville, 2010. WERKEMA, Maria Cristina Catarino. Criando a cultura Seis Sigma. 2. ed. Belo Horizonte: Werkema Editora, 2012. 